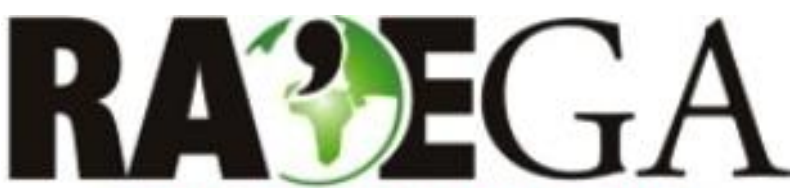

O ESPAÇO GEOGRÁFICO EM ANÁLISE

\title{
A DISPERSÃO URBANA EM MOÇAMBIQUE: UMA CONTRIBUIÇÃO AO ESTUDO DA PRODUÇÃO DO ESPAÇO URBANO EM MAPUTO
}

\section{THE URBAN SPRAWL IN MOZAMBIQUE: A CONTRIBUITION FOR URBAN SPACE PRODUTION STUDIES IN MAPUTO}

\author{
Joaquim Miranda Maloa ${ }^{1}$, Lindberg Nascimento Júnior ${ }^{2}$,
}

\section{RESUMO}

Promovida, principalmente, pela inclusão dos automóveis nos modos de vida urbano, a dispersão urbana é um tipo de constituição de cidades caracterizada pela ocupação do solo com baixa densidade populacional em áreas periféricas no núcleo urbano consolidado. Dentre os principais impactos que decorrem desse modelo de urbanização estão: a crescente demanda de consumo de energia e de recursos naturais; ocupação de áreas ambientalmente frágeis ou suscetíveis a desastres naturais; e aspectos negativos relacionados à qualidade de vida e à saúde da população. A partir de uma análise geográfico-histórica e tomando como exemplo a cidade de Maputo, este artigo evidencia como a degradação ambiental, a segregação socioespacial e a periferização estruturam-se como particularidades da dispersão urbana em Moçambique. Conforme observado em outros países, a dispersão urbana em Moçambique também se configura como mais um obstáculo para implantação de políticas públicas e para a universalização do acesso a bens fundamentais (infraestrutura e serviços). Ela também tende a reforçar, ampliar e cristalizar problemas históricos, presentes na formação socioespacial moçambicana, ainda não resolvidos na atualidade.

Palavras-chave: Urbanização Dispersa; Cidade Dispersa; Maputo; Moçambique

\section{ABSTRACT}

The urban sprawl is a type of urbanization that was characterized by low-population land use in peripheral areas. It is promoted mainly by the inclusion of cars in urban life-styles. In general, the urban sprawl shows impacts in the growing demand for energy and natural resources; occupancy of areas environmentally fragile or susceptible to natural hazards; and aspects related to the quality of life and health of the population. From a geographic-historical analysis, we use the example of urban spatial production in Maputo, and we show how the environmental degradation, the socio-spatial segregation and peripheralization structures are particularities of urban dispersion in Mozambique. As observed in other countries, the urban sprawl in Mozambique is also an obstacle to implementation of public policies and universalization of the urban infrastructure and services. It also trends to reinforce, amplify and crystallize historical processes still unresolved in Mozambican socio-spatial formation.

Key-words: Urban Sprawl; City Spraw; Maputo; Moçambique.

Recebido em: 18/02/2017

Aceito em: 08/02/2018

\footnotetext{
1 Universidade Católica de Moçambique, Lichinga/LX, e-mail: joaquimmaloa@gmail.com

2 Universidade Federal de Santa Catarina, Florianópolis/SC, e-mail: lindberg.junior@ufsc.br
} 
Maloa, J. M.; Nascimento Júnior, L.

\section{A DISPERSÃO URBANA EM MOÇAMBIQUE: UMA CONTRIBUIÇÃO AO ESTUDO DA PRODUÇÃO DO ESPAÇO URBANO EM MAPUTO}

\section{INTRODUÇÃO}

Autores como Araújo (2002; 2003; 2006), Folio (2007), Baia (2011), Serra (2012) e Maloa (2012) já analisaram a constituição do espaço urbano moçambicano e representam um significativo avanço no conhecimento sobre questões relacionadas à urbanização em Moçambique.

Este texto corresponde a uma abordagem que se pretende inovadora, uma vez que ainda é recente uma abordagem teórica que problematize e ofereça instrumentos interpretativos da urbanização moçambicana a partir do processo de dispersão urbana.

Como um modelo de urbanização contemporânea, observada em escala mundial, a dispersão urbana é caracterizada lato sensu pela ocupação do solo com baixa densidade populacional em áreas periféricas ao núcleo urbano consolidado, as quais conjugam diferentes formas de uso e cobertura da terra (ONU, 2012).

Em outras palavras, a dispersão urbana trata-se da emergência de configurações urbanas dispersas, descontínuas e demograficamente heterogêneas. Ela é distinta da tradicional cidade compacta, e evidencia-se em importantes implicações na mobilidade urbana (LOJKINE, 1997).

No caso das cidades moçambicanas, compreender a dispersão urbana é interpretála para além da natureza do crescimento urbano ou pela taxa de urbanização (valor obtido pela razão entre habitantes na zona rural e urbana) e da configuração da forma urbana (estrutura física do ambiente construído), como tradicionalmente tem sido realizado (ARAÚJO, 2002; 2003; 2006).

Nesse sentido, o interesse é pôr em cheque a visão clássica da configuração urbana de tradição colonial que, neste caso, é colocada como ponto de partida para extrair outras interpretações complementares sobre a urbanização em Moçambique. Com isso, visouse contribuir com mais uma leitura dos problemas históricos, teóricos e reais das cidades moçambicanas.
O objetivo é descrever como a dispersão urbana em Moçambique auxilia no aprofundamento dos níveis de segregação socioespacial historicamente produzidos no país, e, ainda, analisar como esse processo age de forma combinada com outros elementos inseparáveis e estimula a permanência de problemas urbanos inerentes à formação socioespacial urbana moçambicana.

Para realizar esse debate, optou-se pelo estudo de caso da cidade de Maputo em função de suas características de crescimento demográfico (estrutura populacional) e metropolitano apresentado nas últimas décadas, além de sua configuração de padrão disperso relativo à existência de áreas ainda não construídas e/ou com baixa infraestrutura urbana.

Para tanto, recorreu-se à pesquisa bibliográfica em que se destacaram diretamente autores da questão urbana moçambicana e de outros países que apresentam a urbanização dispersa como processo explicativo da cidade contemporânea. Além disso, foram utilizados mapas temáticos, documentos oficiais, registros fotográficos e trabalhos de campo.

Para viabilizar a discussão, o texto foi divido em três partes. Na primeira, fez-se uma breve revisão do que se entende atualmente por dispersão urbana. A tentativa foi de enquadrar alguns elementos teóricos julgados como necessários ao entendimento do processo em sua totalidade (LEFEBVRE, 1975; NASCIMENTO $J r$, 2017). Organizou-se para isso um sistema referencial que estabelece a universalidade e particularidade da dispersão urbana em Moçambique e as suas singularidades na cidade de Maputo.

Em seguida, no segundo momento, recorreu-se a uma narrativa geográfica e histórica que revela como a dispersão urbana tem sido um dos fundamentos da segregação socioespacial na produção do espaço urbano das cidades moçambicanas.

Na última parte, apontam-se os pontos de contato e de divergência que corroboram e/ou contradizem o processo de dispersão 


\section{A DISPERSÃO URBANA EM MOÇAMBIQUE: UMA CONTRIBUIÇÃO AO ESTUDO DA PRODUÇÃO DO ESPAÇO URBANO EM MAPUTO}

urbana como modelo universal, e seus ajustes enquanto particularidade e singularidade na realidade urbana de Moçambique e da cidade de Maputo.

\section{Dispersão urbana: urbanização e cidade dispersa}

As transformações e mudanças no conteúdo do urbano, na forma das cidades e nos modelos de urbanização têm produzido configurações fragmentadas, descontínuas e de baixa densidade, que se diferem sobremaneira da tradicional cidade compacta (ABRAMO, 2007; GONÇALVES, 2011). Atualmente, a dispersão urbana é uma das principais características dessas transformações.

A designação - dispersão urbana - é equivalente ao "urban sprawl" do inglês e a "étalement urbain" do francês. Em geral, as terminologias explicam a expansão horizontalizada, espraiada, descontínua, não compacta do tecido urbano, da malha urbana ou do ambiente urbano construído etc. (BRUECKNER, 2000; BURCHELL et al., 2005; EEA, 2006; GARDEN, 2009; EID, et al., 2008; SIQUERE, 2003; THOMPSON, 2013; TSAI, 2005; ZAO e KAETNER, 2010).

Para Oliva (2004) e Silva (2013), tratase de um processo de aglomeração urbana espraiada, que trata da extensão do espaço urbano configurada pelo tecido urbano (cidade). Desse modo, conformam-se os núcleos urbanos dispersos e territorialmente desagregados do conjunto urbano principal.

Segundo Spósito (2007), a dispersão urbana é um tipo específico de expansão do tecido urbano que se expressa pelo espraiamento em rupturas e descontinuidades, com redefinições das lógicas de distribuição espacial dos usos residenciais, industriais, comerciais.

Já Limonad (2007, p.41) interpreta a dispersão urbana como uma estratégia de diferentes grupos sociais para maximizar sua mobilidade espacial e acompanhar a crescente fluidez da mobilidade espacial do capital como meio de garantir sua própria reprodução e sobrevivência e, por que não, uma busca por segurança e por uma melhor qualidade de vida.

De forma abrangente, Bruegmann (2005) entende que a dispersão urbana é um fenômeno que esteve presente desde as vilas das elites na Roma antiga aos bairros construídos fora das muralhas na Europa medieval. Para o autor (2005), o sentido da dispersão urbana se dava no distanciamento, sendo esse elemento considerado fator de comodidade.

Atualmente, o sistema interpretativo da urbanização dispersa tem mudado de qualidade. E essa transformação se dá na medida em que a expansão do tecido urbano acaba por se diluir, inicialmente limitado pelos padrões de densidade urbana que configurava a cidade compacta, e atualmente pela introdução dos automóveis no modo de vida urbano. Além disso, soma-se a oferta de outros condicionantes, como as questões relativas à acessibilidade, da relação entre distância e mobilidade, e da viabilidade técnico-financeira (BRUEGMANN, 2005, p. 33).

Sobre esse aspecto, os automóveis permitiram outro nível de mobilidade na cidade, e sua massificação, nas primeiras décadas do século XX antecedentes à Primeira Grande Guerra, promoveu a construção das "cidades dos automóveis".

As cidades dos automóveis são um marco histórico específico, sendo mais expressivo e consolidado no pós-Primeira Guerra Mundial, a partir da "[...] implantação de sistemas de transporte urbano, primeiramente por trilhos (bondes e trens suburbanos, seguidos pelo metrô) e depois, o de matriz automotiva (ônibus, carros, caminhões, motos etc.) geraram condições técnicas e funcionais para uma cidade mais expandida" (SPÓSITO, 2010, p. 72).

Esse aspecto dotou a cidade menos compacta, "[...] alcançando a situação de dispersão do tecido urbano e de diluição clara das formas urbanas em amálgamas em que elas se mesclam aos espaços rurais nas franjas deste tecido" (SPÓSITO, 2010, p. 72). 


\section{A DISPERSÃO URBANA EM MOÇAMBIQUE: UMA CONTRIBUIÇÃO AO ESTUDO DA PRODUÇÃO DO ESPAÇO URBANO EM MAPUTO}

O uso de automóveis também ofereceu outra qualidade ao desenvolvimento urbano, uma vez que a expansão da cidade poderia se dar em e para qualquer direção. Em síntese, a dispersão urbana foi mais possível com a introdução do automóvel, pois esse mecanismo ofereceu ao espaço urbano uma produção mais rápida e intensa de expansão (NEWMAN e KENWORTHY, 1999, p. 31).

Por essa natureza, conforme Hasse e Lathrop (2003), tal modelo de urbanização pode ser entendido como uma forma distinta de crescimento urbano: disperso, ineficiente, descontínuo na configuração e altamente dependente do automóvel. Assim, a teoria da dispersão urbana sugere que o processo se dá muito mais enquanto forma, no sentido, que sua materialidade é observada pela configuração da estrutura territorial, do ambiente construído, da aparência do urbano, do tecido urbano, etc.

De fato, a cidade, enquanto forma, é a protagonista e a questão central do processo de dispersão urbana, mas entendê-la sob o processo de urbanização é inseri-la dentro de um contexto mais amplo. Isto é, um contexto totalizante na medida em que é também um processo social, histórico, geográfico e político (TANAKA, 2007; AMARO, 2016; BERNARDES, 2007; RIBEIRO, 2010; SPÓSITO, 2007).

Nesse sentido, a cidade e a urbanização dispersa são mais uma forma da expressão espacial do modo de produção capitalista e das lógicas de reprodução das relações sociais de produção (LEFEBVRE, 1975).

A cidade enquanto materialização dos processos de produção que, além da descrição da distribuição espacial dos equipamentos, da identificação de padrões urbanos e da orientação da produção do espaço urbano, expressa a situação e as lógicas contraditórias e desiguais do desenvolvimento do capitalismo.

Nessa perspectiva, a interpretação da dispersão urbana além de ser tomada pela expansão do tecido urbano, é submetida também ao crivo de outros debates - da qualidade de vida e do modo de vida nas cidades. Por sua vez, esse debate se revela não só enquanto elaboração de muitos conceitos, conforme já se destacou, mas principalmente a partir da associação desses com outros processos de mesma medida que organização a questão urbana no momento atual.

Ojima et al. (2015), por exemplo, mostram que a característica socioespacial da expansão do tecido urbano em forma dispersa se encontra na ocupação do solo de forma fragmentada, com baixa densidade populacional, por vezes, sem condições de infraestrutura, sob degradação ambiental e de áreas susceptíveis a diversos riscos naturais.

A esse respeito, o primeiro processo articulado à urbanização dispersa é, sem dúvida, relativo à suburbanização que se deu principalmente nos anos 1990, no contexto norte-americano, sendo que a expressão qualificada desse processo no Brasil se deu em pelo menos duas dimensões: auto-segregação e periferização (OJIMA e MARANDOLA JR., 2016).

A primeira dimensão se dá enquanto possibilidade financeira e econômica de condições de localidade e moradia. A autosegregação é baseada no poder de decisão e da escolha fundamentada no uso da cidade em espaços fechados ou em condomínios murados que, por vezes, podem estar ou não distantes do centro (OJIMA e MARANDOLA Jr, 2016).

A segunda acontece na mesma condição que a primeira, porém se distingue pela qualificação de áreas habitadas pela população. Nesse caso, o acesso aos terrenos e à moradia, muitas vezes, afastados do centro, não funciona como um fator de decisão deliberada, mas uma imposição de quais lugares a população mais pobre deve morar. Habitualmente, são áreas parcamente atendidas por serviços de transporte, abastecimento de água, infraestrutura, eletricidade, etc (OJIMA e MARANDOLA Jr, 2016).

Caracterizados pela densidade construtiva e pela consolidação de núcleos urbanos dissociados, os dois processos auxiliam concomitantemente na oferta e na instalação de equipamentos sociais de uso coletivo (hospitais, 


\section{A DISPERSÃO URBANA EM MOÇAMBIQUE: UMA CONTRIBUIÇÃO AO ESTUDO DA PRODUÇÃO DO ESPAÇO URBANO EM MAPUTO}

escolas, áreas de lazer). Sob uma lógica induzida, tais equipamentos são o sinal de aceleração e seletividade dos processos de segregação socioespacial e de desigualdade na cidade.

No contexto global, Garden et al. (2009) apresentam que a urbanização dispersa também se associa como um problema de saúde pública. Para tanto, esses autores se apoiam nas teses discutidas de Zhao e Kaestner (2010) e da Organização Mundial da Saúde (World Health Organization) (WHO, 2003).

Tais estudos mostraram que o modelo de cidades dispersas se associa às características da diminuição das caminhadas e da prática de esportes e ao consumo de fastfood. Essa situação tem promovido não só o sobrepeso e a obesidade das populações que vivem na cidade, mas também o risco de doenças cardiovasculares, diabetes e certos tipos de câncer.

Segundo Amaro (2016), esse quadro é preocupante, uma vez que a falta de prevenção da obesidade e o aumento intenso de automóveis por longas distâncias significam também uma população menos produtiva, e um sistema público com maiores gastos no setor da saúde.

Por outro lado, Eid et al. (2008) evidenciam que a relação entre urbanização dispersa e os índices de obesidade ainda não estão claramente explicados. Nos Estados Unidos, esses autores observaram indivíduos ao longo do tempo, e as evidências encontradas foram suficientes para afirmar que a relação entre dispersão urbana e saúde humana está equivocada.

Para Eid et al. (2008), a cidade dispersa se relaciona com significância maior dos níveis socioeconômicos (diferentes rendimentos salariais e contextos étnico-raciais principalmente) e das características individuais de residência (tipo e material construtivo) como mecanismos causadores das doenças de acordo com suas diferenças observadas.

Outro rebatimento do processo de dispersão urbana é o encarecimento por distância. Tal aspecto está relativo à especulação imobiliária e à oferta de serviços públicos e coletivos, como energia, abastecimento de água, produção de alimentos que são valorizados diferencialmente segundo a disponibilidade e proximidade dos consumidores (indivíduos e corporações).

Os aspectos contraditórios da dispersão urbana se dão também na dimensão ambiental. Neste caso, os impactos são observados substancialmente por meio do consumo exagerado de recursos naturais (terra, água, energia) nos custos de instalação de infraestrutura urbana. (BRUEGMANN, 2005; AMARO, 2016).

O quadro sugere, assim, a interpretação de uma série de mudanças de uso e ocupação do solo que são acompanhadas de impactos ambientais, que diminuem o desempenho em funções ecológicas básicas e da função social da terra urbana (LEAL, 1998; IBG, 2011; MIRANDA, et al., 2005).

Em geral, pode-se inferir que a dispersão urbana se configura por suburbanização, auto-segregação, periferização, especulação imobiliária e degradação ambiental. Esses processos sugerem ser os principais rebatimentos na escala mundial. Eles são também produtos de uma mesma medida, uma vez que todos estão estruturados e organizados sob a lógica de apropriação do espaço urbano que, por diversas maneiras, diferentes níveis e várias intensidades, tendem a ampliar as desigualdades e a qualidade de vida nas cidades.

$E$, como um fato, esses processos não se restringem a contextos específicos e pontualmente localizados no mundo. Pelo contrário, tratam-se de um modelo universalmente globalizado, que mostra a realidade atual do modo de vida urbano e da constituição das cidades em todo o mundo que se apresenta como uma tendência de igualização (SMITH, 1989).

Por essa razão, tal modelo deve ser entendido como um momento no movimento de totalização (LEFEBVRE, 1975), por isso, é 


\section{A DISPERSÃO URBANA EM MOÇAMBIQUE: UMA CONTRIBUIÇÃO AO ESTUDO DA PRODUÇÃO DO ESPAÇO URBANO EM MAPUTO}

interessante submetê-lo à observação e à análise no território moçambicano.

\section{A urbanização moçambicana e a dispersão urbana em Moçambique \\ O território moçambicano abrange uma} área de $799.379 \mathrm{~km}^{2}$ e apresenta o total de 20,5 milhões de habitantes, dos quais 35\% (7,5 milhões de pessoas) concentram-se nas áreas urbanas (UNHABITAT, 2007).

Em termos de divisão administrativa, Moçambique está dividido em onze províncias. A cidade de Maputo é a capital e está localizada na província do mesmo nome. As províncias contemplam três regiões, sendo que a Região Norte compreende as províncias de Niassa, Cabo Delgado e Nampula; a Região Centro, Zambézia, Tete, Manica e Sofala; e a Região Sul, Inhambane, Gaza, Maputo-província e Maputocidade (Figura 1).
Do ponto de vista da questão urbana, as cidades em Moçambique foram construídas, historicamente, dentro da matriz colonial, isto é, com acesso a recursos e portos para a exportação. O Estado colonial organizou o território utilizando instrumentos de diferenciação social e racial, pela Lei de Concessão de Terra de 1899 e pela Lei de Reservas de Terras Indígenas de 1909 (DIREITO, 2014).

Com esses instrumentos legislativos, a distinção entre moçambicanos e não moçambicano, do ponto de vista do uso, do acesso e do controle sobre a terra, era defendida nas Cortes, em nome da valorização econômica dos territórios coloniais e da salvaguarda da soberania portuguesa na África (DIREITO, 2014).
Figura 1 - Divisão Moçambique. Fonte:

As cidades moçambicanas, nesse contexto, foram construídas na segregação e para a segregação. A organização espacial expressava a concentração de brancos e negros

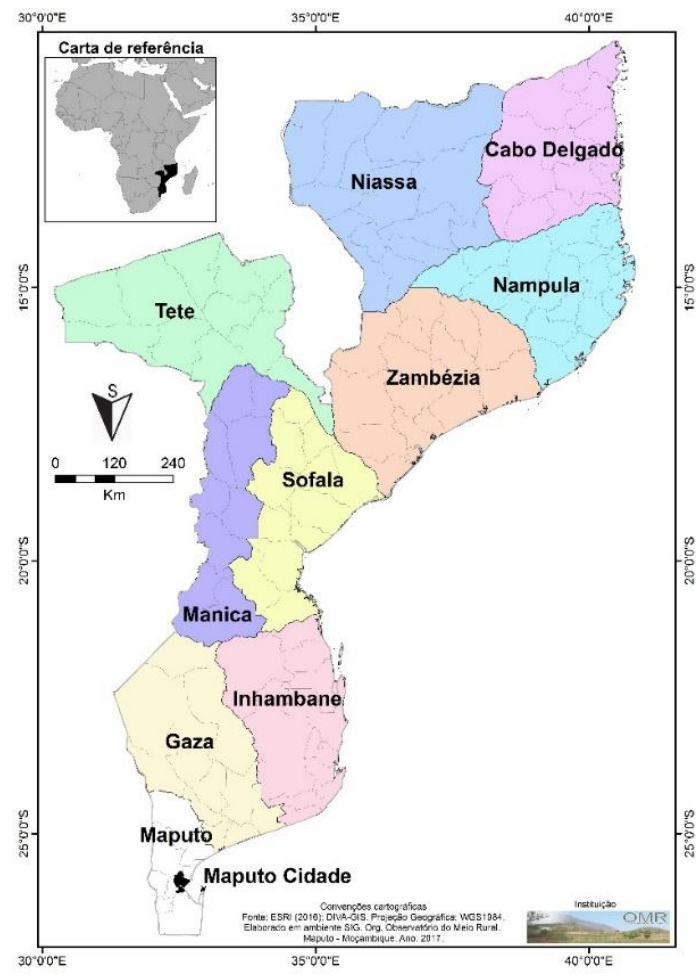

Administrativa de Autores. "assimilados" ricos nas áreas centrais da cidades, chamadas de Cidade de Cimento enquanto os negros pobres eram distribuídos nas áreas periféricas ou no entorno da Cidade de 
Maloa, J. M.; Nascimento Júnior, L.

\section{A DISPERSÃO URBANA EM MOÇAMBIQUE: UMA CONTRIBUIÇÃO AO ESTUDO DA PRODUÇÃO DO ESPAÇO URBANO EM MAPUTO}

Cimento. Essas áreas na cidade foram tradicionalmente chamadas de Cidade de Caniço.

Segundo Morais (2001), a divisão entre a Cidade de Cimento e a Cidade de Caniço mostrava, de um lado, uma urbanização qualificada, dotada de infraestrutura, saneamento, eletricidade, etc.,; e do outro, uma urbanização precária. Assim, a produção do espaço urbano das cidades moçambicanas evidencia o momento político de segregação socioespacial historicamente concebida, que separa física e culturalmente grupos de classes sociais distintos.

Em 1975, depois da independência nacional, com a libertação moçambicana contra o colonialismo português, uma guerra civil entre a Frente de Libertação de Moçambique (FRELIMO) e a Resistência Nacional de Moçambique (RENAMO), nos anos de 1977 a 1992, irrompeu o país. Nesse contexto, a infraestrutura, as estradas e as pontes tornaram-se alvos a serem abatidos, enquanto as cidades receberam pressão populacional adicional, sendo basicamente constituídas de populações rurais refugiadas.

Com o fim da guerra civil em 1992, com a assinatura do Acordo Geral de Paz de Roma (1992) e a realização das primeiras eleições presidenciais e legislativas (1994), o novo governo eleito foi confrontado com o desafio de reconstruir as infraestruturas urbanas destruídas pela guerra civil, uma vez que milhares de moçambicanos tornaram-se "deslocados de guerra" nos centros urbanos.

Araújo (2003) ressalta que devido à guerra as pessoas procuravam os centros urbanos, preenchendo todos os espaços não ocupados; estes, por sua vez, eram basicamente formados por áreas destinadas a jardins, protegidas, pantanosas, lixeiras, implantação de infraestruturas e serviços urbanos.

$O$ resultado foi que a constituição das cidades em Moçambique avolumou-se com habitações precárias. De tipo horizontal, além de ampliar as condições de diferenciação entre o centro (cidade de cimento) e a periferia (cidade de caniço), o espaço urbano foi caraterizado por uma morfologia ortogonal e radioconcêntrica.

Conforme Baia (2009), esse processo também orientou um modo de vida urbano híbrido, que se dá pela coexistência de dois processos de produção do espaço urbano: uma urbanização nativa: derivada de sociedades africanas pré-coloniais, apoiadas nos sistemas de linhagem e por ruralidades; e outra, uma urbanização ocidentalizada: marcada por lógicas modernas e industriais de habitar e viver na cidade.

A produção do espaço urbano moçambicano é, assim, concomitantemente constituída por esses dois modos de vida, em que ambos centralizam e promovem o movimento da sua reprodução no espaço urbano (BAIA, 2009).

Dois exemplos representativos desses contextos podem ser aqui associados. 0 primeiro se dá na observação de áreas iluminadas em Moçambique (obtidas por imagem de satélite luzes noturnas, conforme Nascimento Jr. (2016) (Figura 2) e a regionalização dos assentamentos informais no território moçambicano, conforme a Direção Nacional de Planeamento e Ordenamento Territorial (DINAPOT, 2006) (Figura 3). 


\section{A DISPERSÃO URBANA EM MOÇAMBIQUE: UMA CONTRIBUIÇÃO AO ESTUDO DA PRODUÇÃO DO ESPAÇO URBANO EM MAPUTO}

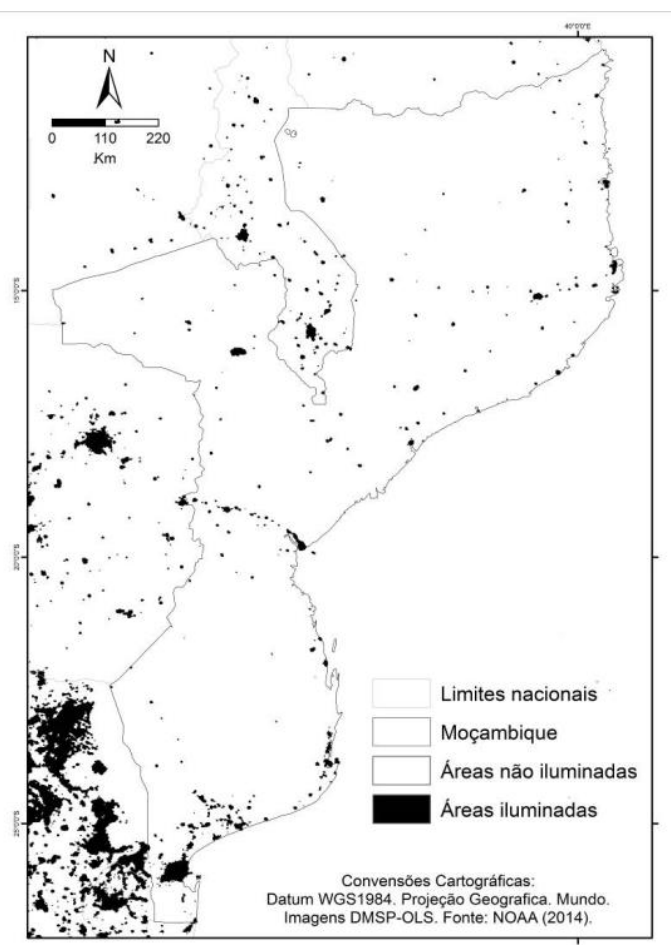

Figura 2 - Áreas iluminadas no território moçambicano como referência de observação de localização áreas urbanizadas/área das cidades. Fonte: Nascimento Jr (2017).

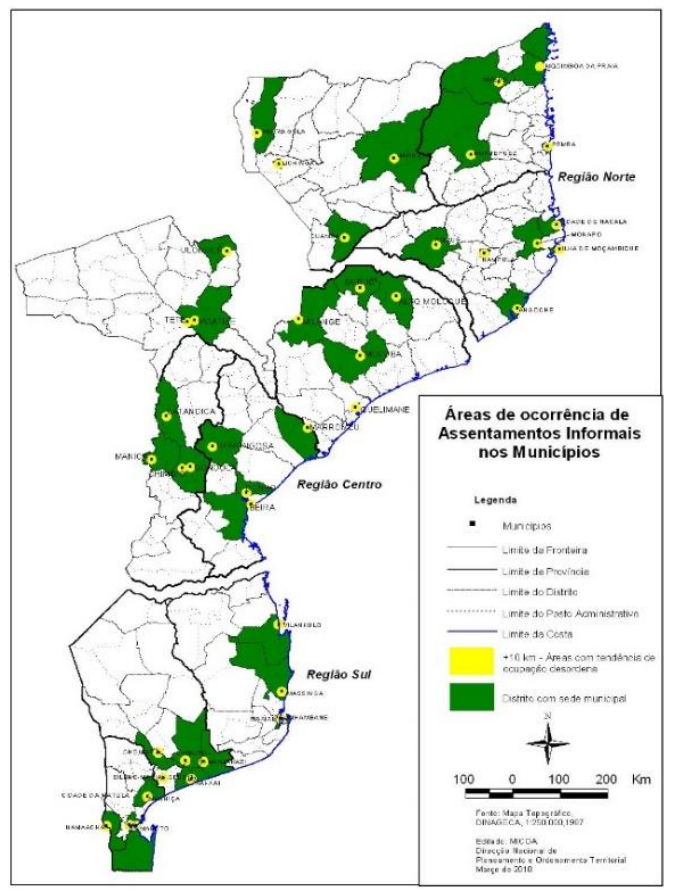

Figura 3 - Assentamos informais em Moçambique, como referência da ocorrência de uma urbanização qualificada em áreas situadas nas principais cidades do país. Fonte: DINAPOT, 2006.

A Figura 2 mostra os processos contraditórios, nos quais as centralidades das cidades na rede urbana (áreas de iluminadas no interior do país) são contrapostas à centralidade principal, representada pela cidade de Maputo 


\section{A DISPERSÃO URBANA EM MOÇAMBIQUE: UMA CONTRIBUIÇÃO AO ESTUDO DA PRODUÇÃO DO ESPAÇO URBANO EM MAPUTO}

(capital do país), no sul do país (NASCIMENTO JR, 2016).

Nesse caso, são as áreas iluminadas, equivalentes às maiores cidades, que apresentam a configuração mais importante de aumento, concentração e intensidade de áreas iluminadas em direção a espaços e a áreas vizinhos. Algo que assegura a urbanização dispersa não só como uma característica de expansão horizontal, conforme inicialmente discutido e proposto por Bruegmann (2005), Botelho (2012), Sposito (2007) e Newman e Kenworthy (1999), mas também elemento de relevância e de consolidação de cidades mais antigas e importantes na rede urbana (NASCIMENTO Jr, 2016)

O segundo exemplo (Figura $2 b$ ) mostra uma relação entre as principais cidades e as áreas com presença de assentamentos informais. Segundo a DINAPOT (2006), trata-se de aglomerados humanos que se caracterizam pela ausência de acesso aos serviços de saneamento, à água potável, a espaço suficiente interior/exterior, a vias de acesso e à habitação segura e durável. São áreas onde as densidades habitacionais é cerca de 70 habitações/Ha, em que os terrenos não estão ordenados ou definidos, além de não possuírem definição de arruamentos e apresentarem sistema deficiente de infraestrutura urbana básica.

Nessa lógica, essas áreas são expandidas, consolidadas, densificadas, e repercutem na saturação dos equipamentos e das infraestruturas e sua insuficiência, na dificuldade de acesso à educação e à saúde, no desemprego e na economia informal, na pobreza urbana, na emergência de problemas ambientais e sociais, entre outros (MELLO, 2013). Algo muito similar aos impactos da dispersão urbana em países como o Brasil, conforme anteriormente explicitado.

Raposo e Salvador (2007) explicam que assentamentos informais são áreas de materialização do sincretismo e interação entre o mundo urbano de origem colonial e ocidental e o mundo rural moçambicano. Nesses locais, os padrões de vida se afastam das referências rurais, mas também não seguem o modelo citadino do centro.

Tal situação foi interpretada por Baia (2009), e Maloa (2016) chamou de acumulação de dualidade urbana em Moçambique. O sentido do conceito utilizado por Maloa (2016) é o de explicar a permanência da configuração dual (Cidade de Cimento e Cidade de Caniço), com novos conteúdos, com outras formas e a mesma organização. O que é, sobretudo preocupante, pois, segundo o Programa das Nações Unidas para os Assentamentos Humanos (UN-HABITAT, 2005), é estimado que $80 \%$ das populações nas cidades moçambicanas vivem em assentamentos informais.

Desse modo, a proposta de relação entre as áreas iluminadas, verificada por meio de imagens de satélites, e a produção de assentamentos informais no território moçambicano parece ser funcional como um indicador de observação da cidade dispersa. Com esse exercício, fica evidente a relação entre periferização e degradação ambiental nos assentamentos informais das principais cidades do país africano, como um dos resultados da urbanização dispersa.

Contudo, apesar do exercício quantitativo e cartográfico a nível nacional se fundamentar enquanto uma particularização do movimento universal do processo de urbanização dispersa é ainda pertinente evidenciar outros níveis de particularização e singularização, recorrendo-se ao exemplo da cidade de Maputo.

\section{Urbanização dispersa na cidade de Maputo} A cidade de Maputo está localizada em 2505' Latitude Sul e $32^{\circ} 40^{\prime}$ de Longitude Leste, na província da Cidade de Maputo, região sul do Moçambique (Figura. 4). No período colonial, a cidade chamava-se Lourenço Marques em homenagem ao navegador das naus da Índia, que fez o reconhecimento geográfico e econômico da Delagoa Bay, em 1544.

A fixação portuguesa em Lourenço Marques iniciou-se com a criação de um presídio em 1781, e em 1805, a cidade foi ocupada por 


\section{A DISPERSÃO URBANA EM MOÇAMBIQUE: UMA CONTRIBUIÇÃO AO ESTUDO DA PRODUÇÃO DO ESPAÇO URBANO EM MAPUTO}

uma força militar e só em 1887 foi elevada a categoria de cidade. Onze anos depois, em 1898, foi promovida a capital da Província Ultramarina de Moçambique. Nesse período, os edifícios foram construídos num traçado regular em quadrícula (MELO, 2013; MENDES, 1979; MORAIS, 2001).

Com a independência nacional, em 1975, o traçado regular em quadrículo começou a ficar compacto com o crescimento da periferia (VIANA, 2010). Essa realidade urbana se acentuou a partir da década de 1980, com a reclassificação administrativa urbana; com a guerra civil que aumentou a migração; e a presença de deslocados da guerra. Estes, como já abordado, construíram suas casas em torno do centro urbano, formando uma acelerada dispersão residencial (MALOA, 2012).

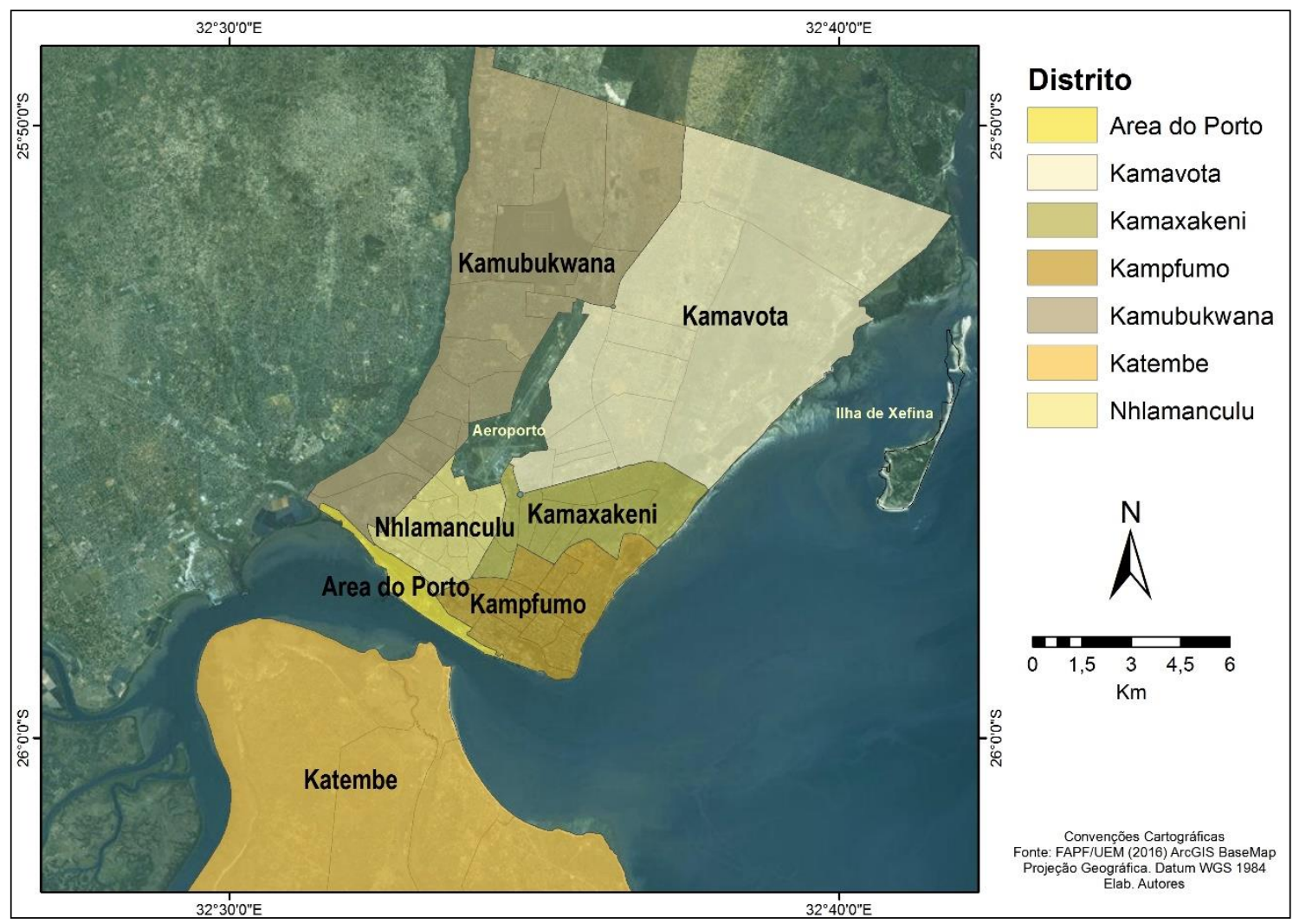

Figura 4 - Divisão Administrativa da Cidade de Maputo. Fonte: Autores.

O caso peculiar desse processo é a grande mancha disposta em torno do centro, que caracteriza uma maior densidade demográfica e de ocupação da terra urbana, delimitando territorialmente a paisagem urbana na dualidade das cidades moçambicanas segundo as características das habitações (Figura 5).

A delimitação da dualidade na cidade de Maputo fundamenta a distinção, em primeiro lugar, da Cidade de Cimento - vertical, ortogonal, com urbanização de infraestrutura qualificada, limitada antigamente pelo arco de circunvalação. Para aquém da linha vermelha e no interior do arco de circunvalação (Figura 5) existe o predomínio de construções horizontais, com forte densidade populacional.

No que se refere à configuração populacional e administrativa, a cidade de Maputo compreendia inicialmente cinco distritos urbanos. Desse conjunto, vale destacar o núcleo mais antigo e mais urbanizado da cidade corresponde ao distrito KaMpfumo, enquanto os distritos de KaMavota e KaMabukwane, localizados nas áreas periféricas, são resultado da expansão do tecido urbano pós-independência. 


\section{A DISPERSÃO URBANA EM MOÇAMBIQUE: UMA CONTRIBUIÇÃO AO ESTUDO DA PRODUÇÃO DO ESPAÇO URBANO EM MAPUTO}
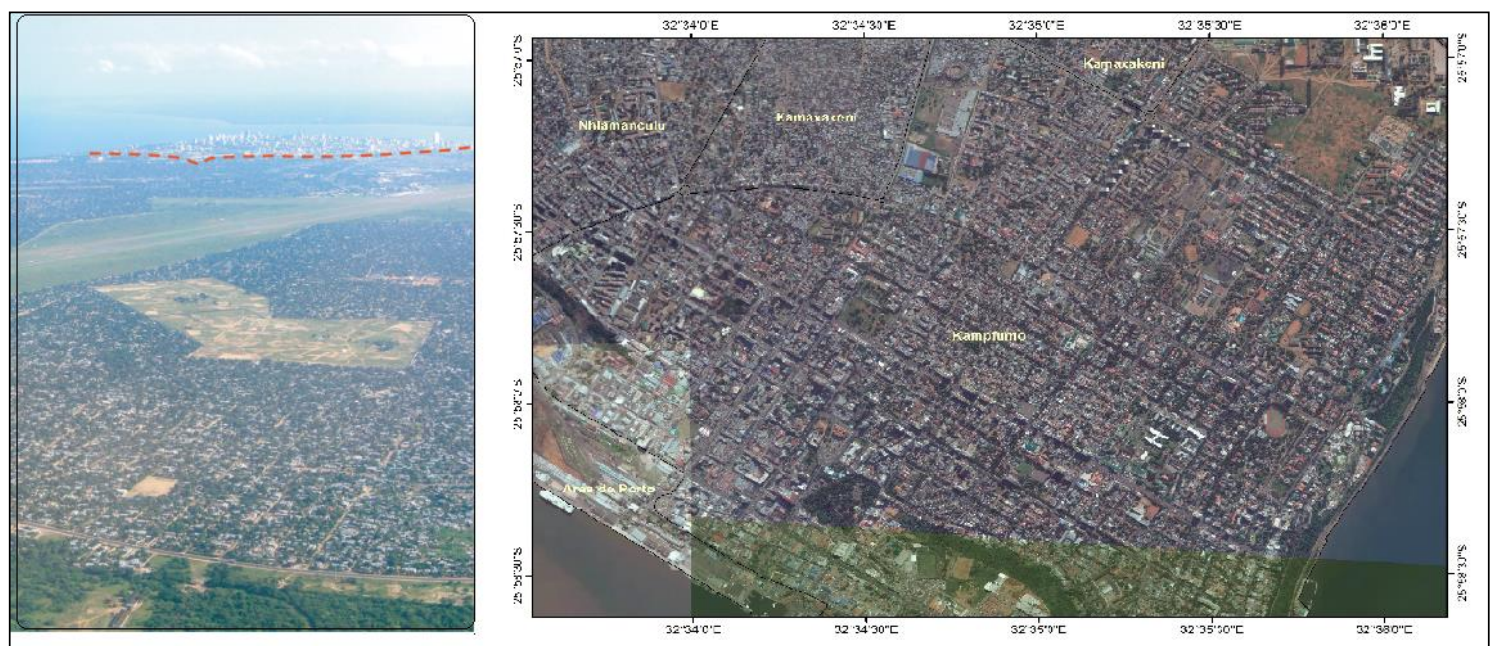

Figura 5 - Vista área de dispersão urbana na cidade de Maputo com delimitação da Cidade de Cimento na linha vermelha, e recorte de imagem de satélite com o arco de circunvalação que representava os limites da Cidade de Cimento. Fonte: Fólio (2007); Autores.

De acordo com Araújo (2006), as construções da KaMpfumo - setor central da cidade - são quase na sua totalidade verticais e registram baixa densidade populacional. Nesse distrito também estão concentradas quase a totalidade das atividades econômicas, administrativas e sociais, sob uma área consideravelmente bem construída, devido à existência de infraestruturas viárias, de áreas de estacionamento e de desporto e lazer.

Segundo Araújo (2006, p. 7), os bairros mais populosos (mais de 30 mil habitantes) localizam-se nos distritos urbanos menos urbanizados. Os distritos de Nhlamanculo e KaMaxaquene representam 9,4\% da área territorial e contemplam mais de metade da população da cidade, cerca de $52,4 \%$ do total. São distritos com uma história antiga de local de residência urbana, que já no período colonial abrigavam muitas populações constituídas por trabalhadores menos favorecidos ou por classes médias baixas.

Atualmente, esses distritos são fundamentalmente constituídos por habitações horizontais e apresentam a maior densidade populacional e construtiva da cidade. Neles, é comum a ausência de áreas para circulação, lazer, estacionamento, jardins, etc. Por isso esses dois distritos já não apresetam áreas disponíveis para novas construções, que seja ainda para edificação de infraestruturas urbanas(ARAÚJO, 2006).

Nesse contexto, a dispersão urbana também tende ocorrer na escala interurbana, abrangendo a área da cidade de Maputo e as áreas vizinhas. $O$ resultado advém da situação que parte da população residente na cidade de Maputo ou migra para as cidades vizinhas, principalmente para Matola, Manhiça, Marracuene e Boane, a fim de erguer novas construções (MENDOÇA, 2012), ou submetemse a viver em áreas com baixa possibilidade construtiva e alta densidade demográfica.

De outro modo, a população de maior poder aquisitivo tem adquirido os terrenos das "casas de caniço desocupadas" pelas populações que saíram da cidade de Maputo, e constroem no lugar residências de grande porte, que por sua vez altera sobremaneira a paisagem urbana.

Que a substituição de "casas de caniço" por "casas de cimento" altera a paisagem urbana é fato, mas isso só acontece apenas na dimensão do ambiente construído, que de forma geral, não muda a condição de precariedade já existente.

Isso por que a grande população maputense continua a conviver com a baixa 


\section{A DISPERSÃO URBANA EM MOÇAMBIQUE: UMA CONTRIBUIÇÃO AO ESTUDO DA PRODUÇÃO DO ESPAÇO URBANO EM MAPUTO}

qualidade de segurança no transporte, dificuldade de acesso à água potável e insuficiência de serviços de saúde, educação e proteção. Tais serviços e infraestruturas são ainda mais reduzidos com a distância, e rebatem diretamente em implicações na mobilidade urbana.

Pode-se inferir desse contexto que é justo falar de urbanização dispersa em Maputo nos termos atribuídos por LojKine (1997), Tanaka (2007), Amaro (2016), Bernaedes (2007), Ribeiro (2010), Spósito (2007), entre outros..

Mas os impactos vão além. Influenciada por construções infraestruturais como a nova estrada circular, a conjuntura atual evidencia-se por construções habitacionais em áreas altamente valorizadas, o que acaba por fortalecer outros processos na produção do espaço - especulação imobiliária, e permanecer e ampliar outros, o da segregação socioespacial por exemplo.

A particularidade da urbanização dispersa se dá em Maputo, na precariedade da moradia e da habitação que pode ser visualizada pela existência de assentamentos informais, representados na Figura 7 (área com cor amarela).

A situação mostra que a configuração urbana da área metropolitana de Maputo é um quadro díptico, utilizando os termos de Viana (2010). Ou seja, ela é o somatório do processo colonial urbano e do pós-colonial que perfaz múltiplas partes enquadradas num mosaico urbano de geometria intrincada (entre a cidade compacta, dispersa e sem forma) que já não espelha apenas a dicotomia "cidade de cimento" versus "cidade de caniço".

Essas duas realidades tendem a desvanecer-se, cruzando-se, sobrepondo-se e justapondo-se a outras que foram ganhando forma e expressão no espaço urbano. Esta nova situação, que engloba a "periferia de caniço" e sua zona mais fortemente povoada, transpõem a coerência da morfologia urbana no espaço construído e no desenho do espaço público. Neste sentido, essas áreas se apresentam,

"[...] com a presença de pequenos centros de bem-estar e de luxo protegido por grades, sistemas de segurança eletrônica e guardas privados, rodeados de hotéis, casas de câmbios, restaurantes, cafés, pastelarias, supermercados, cassinos e bombas de gasolina" (SERRA, 2012, p.192).

Tal característica expressa o quadro dicotômico de desenvolvimento histórico da cidade de Maputo e de sua urbanização dual já discutida por Araújo (2002; 2003; 2006), Folio (2007), Baia (2011), Serra (2012) e Maloa (2012), e pode ser mais bem visualizada na configuração da malha urbana (Figura 6), em que, na cidade de cimento, predomina no setor central e em outros setores dispersos e mais recentemente construídos o tipo xadrez com arco da circunvalação (ALTVATER, 2005). 


\section{A DISPERSÃO URBANA EM MOÇAMBIQUE: UMA CONTRIBUIÇÃO AO ESTUDO DA PRODUÇÃO DO ESPAÇO URBANO EM MAPUTO}

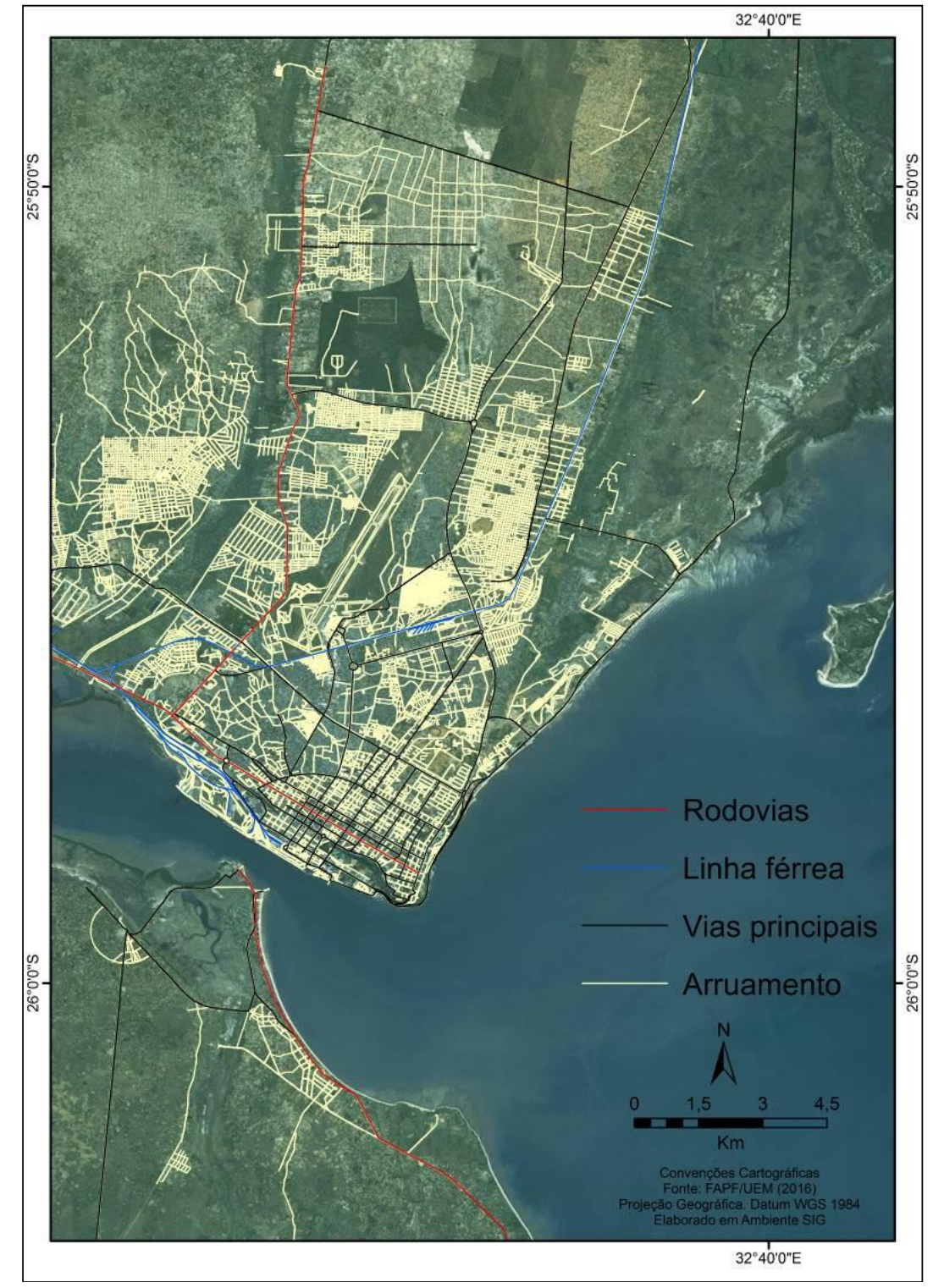

Figura 6 - Malha urbana e arruamento da cidade de Maputo. Fonte: Autores.

Pela quantidade e qualidade de vias é possível estabelecer que sejam áreas providas de infraestruturas urbanas adequadas, pois apresentam quarteirões e arruamento bastante ordenados (traçado reticular, do tipo tabuleiro). São também áreas mais privilegiadas socioeconomicamente, pois contemplam setores com os domicílios de elevados rendimentos, em parte em função da boa qualidade das infraestruturas.

No seu oposto, configurados por um sistema de arruamento, os bairros são formados majoritariamente com a auto-organização e por habitações dos grupos sociais pobres, desprovidos de infraestrutura e serviços, em que se identifica o modelo de traçado rizomático. Esse modelo consolida e expressa o enquadramento a cidade de caniço moçambicana (ALTVATER, 2005; KRÜGER, 2012; VIANA et al., 2013), cujo resultado é a formação de assentamentos informais, que estão situados em grande parte da área da cidade, correspondendo a situação no âmbito nacional. 
Maloa, J. M.; Nascimento Júnior, L.

\section{A DISPERSÃO URBANA EM MOÇAMBIQUE: UMA CONTRIBUIÇÃO AO ESTUDO DA PRODUÇÃO DO ESPAÇO URBANO EM MAPUTO}

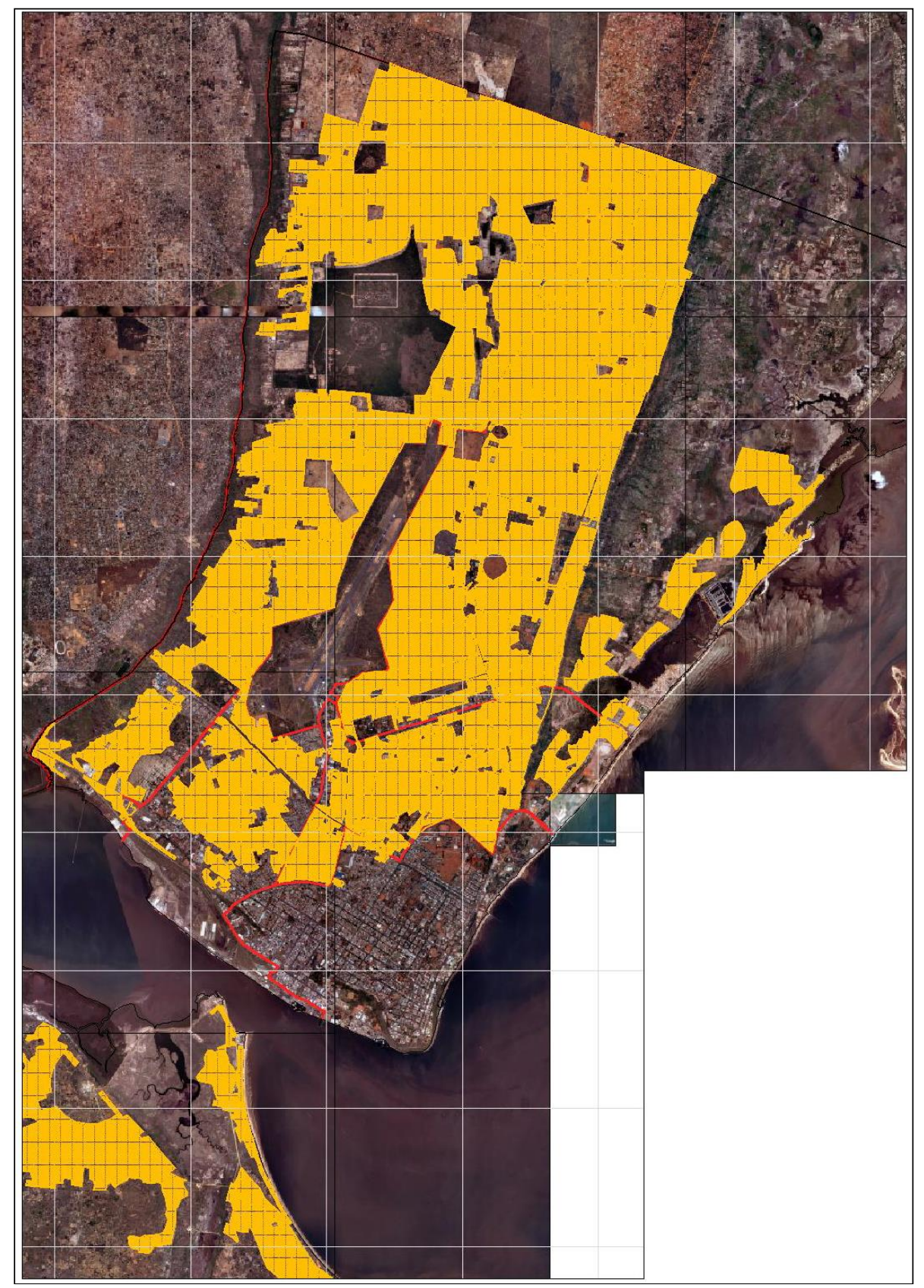

Figura 7 - Assentamentos informais (área na cor amarela) em Maputo. Fonte: CCM (2016).

Conforme analisado até o momento, Maputo é uma cidade eminentemente dual (em se tratando de tipo de urbanização) e mestiça (segregação socioespacial e racial), por isso, pode-se inferir que os fundamentos da segregação socioespacial e da urbanização precária parecem não ser um processo novo no estado moçambicano e nem na área metropolitana.

Em outras palavras, a cidade de Maputo evidencia a heterogenia, profundamente alotrópica, e apresenta o permanente incesto entre casas de cimento e as casas de caniço (SERRA, 2012, p. 279), que caracteriza um turbulento e polifágico estado de akrasia (incontinência) (SERRA, 2012, p. 193; VIANA, 2010).

Como mostrou Mendes (1979, p. 13), a cidade de Maputo no período pósindependência já esboçava a fisionomia de expansão urbana do período colonial, onde as construções já eram dispersas. As combinações 


\section{A DISPERSÃO URBANA EM MOÇAMBIQUE: UMA CONTRIBUIÇÃO AO ESTUDO DA PRODUÇÃO DO ESPAÇO URBANO EM MAPUTO}

das conjunturas atuais, como, por exemplo, da dispersão urbana efetivam-se muito mais enquanto um reforço das desigualdades e da segregação socioespacial do que de transformação do ambiente urbano.

Não obstante, Maputo ainda exerce no país uma função metropolitana. A cidade apresenta, neste momento, uma importante reestruturação basicamente populacional e econômica, ou seja, um veloz crescimento da população, novos dinamismos econômicos, segmentos comerciais e de serviços, empreendimentos e bairros para moradores de renda mais elevada. Contudo, na mesma medida tem sido observada baixa eficácia na inclusão da maioria da população, como se a reestruturação fosse um movimento natural, inevitável e irreversível.

Nesse aspecto, ressalta-se o transporte intraurbano e interurbano de Maputo para as cidades da Matola e Boane.Por meio dele os trabalhadores mais precarizados são transportados em condições perigosas. Basicamente, utilizam-se veículos do tipo camionete (conhecidos por My love), com os potenciais riscos decorrentes, justamente pelo transporte acontecer com as pessoas agarradas umas às outras nas carrocerias.

É justamente por esses fatores que a dispersão urbana tende a reforçar a existência dos assentamentos informais e a precariedade na mobilidade como um marco territorial nas cidades moçambicanas. Nesse processo, o processo tende a ampliar e cristalizar os processos históricos não resolvidos na atualidade, e ainda presentes na formação socioespacial moçambicana.

\section{CONSIDERAÇÕES FINAIS}

Apesar de ainda ser necessário um aprofundamento nos estudos para relacionar a dispersão urbana com aas cidades moçambicanas, em termos de gênese, conteúdo e formas, aproximações foram realizadas a partir da conjugação de alguns atributos do processo de urbanização inerentes à formação socioespacial de Moçambique.

A leitura da dispersão urbana em Moçambique parece fundamentar uma duplicidade entre periferização - degradação ambiental, e se efetiva de maneira significativa na constituição dos assentamentos informais, observados em grande parte nas cidades de grande porte, como Maputo, Beira e Nampula. Nessas cidades aumentam-se a construção de residências em áreas distantes dos centros com implicações também na mobilidade urbana. Essa seria a particularidade de Moçambique em comparação aos estudos desenvolvidos sobre o tema.

Isso significa também dizer que a dispersão urbana em Moçambique se efetiva principalmente na precariedade seletiva das infraestruturas, dos serviços e das condições habitacionais e ambientais, historicamente desenvolvidas, e não somente na expansão do tecido urbano, enquanto particularidade da face do urbanização dispersa enquanto periferização - degradação ambiental.

$\mathrm{Na}$ cidade de Maputo, essas características foram facilmente identificadas pela configuração da paisagem, da malha urbana, na constituição populacional e habitacional. Recentemente, devido à importante metropolização, essas características também ocorrem em integração nos municípios de Matola, Boane, Marracuene e Manhiça, mas outros estudos deverão ser desenvolvidos também sobre esses aspectos.

Vale destacar que a dispersão urbana configura-se como um problema nas cidades moçambicanas. Isso por que ela traz obstáculos para a implantação de políticas públicas e para a universalização do acesso a bens fundamentais, sendo isso uma das características da mobilidade urbana.

Com esses resultados é possível realizar trabalhos futuros que levem em consideração também o papel do processo metropolização das cidades moçambicanas e em particular da cidade de Maputo. Isso por que, como processo é organizado e estruturado 


\section{A DISPERSÃO URBANA EM MOÇAMBIQUE: UMA CONTRIBUIÇÃO AO ESTUDO DA PRODUÇÃO DO ESPAÇO URBANO EM MAPUTO}

junto com dispersão urbana, a marcha do crescimento urbano só deve induzir cada vez mais a urbanização dual clássica, na mesma seletividade e desigualdade, ou ainda maior, quanto incorpora os aspectos da urbanização conteporânea.

Isso por que a dispersão urbana em Moçambique se combina à forte segregação socioespacial da urbanização clássica, se configurando como uma permanência, pois de um lado mostra parte da história das cidades, e do outro consolida a relação desigual e dual do que tem sido explicado como central e periférico nas cidades moçambicanas.

No entanto, ainda falta demostrar como a dispersão urbana em Moçambique e em Maputo se efetiva também enquanto autosegregação, pois já se verifica a instalação de condomínios fechados em áreas periféricas de algumas cidades.

\section{REFERÊNCIAS}

ABRAMO, P. A cidade com-fusa: a mão inoxidável do mercado e a produção da estrutura urbana nas grandes metrópoles latinoamericanas. Revista Brasileira de Estudos Urbanos e Regionais, 9(2), 2007, p.25-54.

ALTVATER, E. Globalization and the informalization of the urban space. In: BRILLEMBOURG, A., FEIREISS, K. e KLUMPNER, H. (eds.). Informal city. Caracas case. Prestel: German Federal Cultural Foundation. 2005,p. 51-7.

AMARO, A. B. O processo de dispersão urbana e a questão ambiental: Uma comparação da literatura estrangeira com o fenômeno no Brasil. In: Revista Formação (online). Presidente Prudente, v. 4, n. 23, set-dez/2016. p. 107-136. ARAÚJO, M. G. M. Espaço urbano demograficamente multifacetado: As cidades de Maputo e da Matola. 2006. Disponível em: www.apdemografia.pt. Acesso em: 08 abr. 2012.

ARAÚJO, M. G. M. Ruralidade - Urbanidade em Moçambique. Conceitos ou Preconceitos? Revista da Faculdade de Letras-Geografia. I série. Vol. XVII-XVIII. Porto, 2002.

ARAÚJO, M. G. M. Os espaços urbanos em Moçambique. Geousp-Espaço Tempo, São Paulo, no 14, p.165-182, 2003.
BAIA, Alexandre. Os meandros da urbanização em Moçambique. GEOUSP - Espaço e Tempo, São Paulo, no29- Especial, p.3-30, 2011.

BERNARDES, C. A dispersão urbana vista pelos empresários. In: REIS, N. G. (Org.). Brasil estudos sobre dispersão urbana. FAU - USP. 2007.

BOTELHO, A. Capital volátil, cidade dispersa, espaço segregado: algumas notas sobre a dinâmica do urbano contemporâneo. Cadernos Metrópole. São Paulo, v. 14, n. 28, jul-dez/2012, p. $297-315$.' $^{\prime}$

BRUECKNER, J. K. Urban Sprawl: Diagnosis and Remedies. International Regional Science Review, vol. 23, n. 2. 2000, p. $160-171$.

BRUEGMANN, R. La dispersión urbana: Uma história condensada. Barcelona: Doce Calle, 2012.

BURCHELL, R. W; DOWNS, A; MCCANN, B; MUKHERJI, S. Sprawl Costs. Economic impacts of unchecked development. Island Press. Washington DC: 2005.

DINAPOT, Direção Nacional de Planejamento e Ordenamento Territorial. Moçambique melhoramento dos assentamentos informais.2006. Disponível em: www.unhabitat.org. Acesso em: 14 jan. 2017.

DIREITO, B. Terra e africanos no pensamento colonial português, c. 1920-c. 1945. Análise Social, p. 768-793, 2014.

EEA. European Environment Agency. Urban sprawl in Europe: The ignored challenge. Office for Official Publications of the European Communities. 2006. Disponível em: <http://www.eea.europa.eu/publications/eea_ report_2006_10>. Accesso in: 30 abr 2015.

EID, J; OVERMAN, H; PUGA,D; TURNER, M. Fat city: Questioning the relationship between urban sprawl and obesity. Journal of Urban Economics, 63, 2008. p. $385-404$.

FOLIO, F. La criminalité à Maputo, Mozambique:origine, distribution et répercussions spatiales. Cybergeo: European Journal of Geography. Espace, Société, Territoire, document $\mathbf{3 8 0}$, mis en ligne le 02 juillet 2007.

GARDEN, F. L; JALALUDIN, B. B. (2009). Impact of urban sprawl on overweight, obesity, and physical activity in Sydney, Australia. Journal of Urban Health, 86(1), 19-30.

GONÇALVES, A. R. Indicadores da dispersão urbana. Dissertação de Mestrado (Planejamento urbano e regional). Universidade 


\section{A DISPERSÃO URBANA EM MOÇAMBIQUE: UMA CONTRIBUIÇÃO AO ESTUDO DA PRODUÇÃO DO ESPAÇO URBANO EM MAPUTO}

Federal do Rio Grande do Sul. Faculdade de Arquitetura. Programa de Pós-Graduação em Planejamento urbano e regional. Porto Alegre. $112 \mathrm{p}$.

HASSE, J; LATHROP, R. A Housing-Unit-Level Approach to Characterizing Residential Sprawl. Photogrammetric Engineering and Remote Sensing, V.69, n. 9, p.1021 - 1030, 2003.

IBGE. Instituto Brasileiro de Geografia e Estatística. Reflexões sobre os Deslocamentos Populacionais no Brasil. Rio de Janeiro: 2011. KRUGER, D. J. 'Integrating Quantitative and Qualitative Methods. In: Community Research. The Community Psychologist, 36, 2003, p. 18-19. Available: http/www.personal.umich.edu, retrieved Sept. 1, 2014.

LEAL, M. S. Princípios de gestão ambiental. Rio de Janeiro: CPRM, 1998.

LEFÈBVRE, H. Lógica formal e lógica dialética. Rio de Janeiro, Civilização Brasileira, 1975.

MENDOÇA I. Mobilidade urbana na área metropolitana de Maputo: análise dos orgãos de gestão do planeamento e mobilidade urbana, arranjos institucionais e insumos para a sua efetivação. Journal of Transport Literature, vol. 8, n. 2, pp. 244-270., 2012.

LOJKINE, J. O Estado capitalista e a questão urbana. 2. ed. Tradução de Estrela dos S. Abreu. São Paulo: Martins Fontes, 1997.

MACEDO, J. A (in)sustentabilidade do desenvolvimento urbano nos Estados Unidos: o que as cidades brasileiras podem aprender com as americanas. Revista Paraense de Desenvolvimento. Curitiba, n. 120, jan./jun. 2011, p. 277-296.

MALOA, J. O lugar da desordem: um estudo sociológico sobre 0 assalto à mão armada em Moçambique, na cidade de Lichinga. Dissertação. (Mestrado em Sociologia) Universidade de São Paulo, São Paulo. 2012.

MALOA, J. A Urbanização moçambicana: uma proposta de interpretação. Tese (Doutorado em Geografia Humana) - Universidade de São Paulo, 1979.

MENDES, M. C. Maputo antes da independência: geografia de uma cidade colonial.1979. Tese (Doutorado em Geografia Humana) - Universidade de Lisboa, 1979.

MELO, Vanessa. Urbanismo português na cidade de Maputo: passado, presente e futuro. URBE Revista Brasileira de Gestão Urbano. Pontifícia Universidade Católica do Paraná- PUCPR, jan/jun 2013, p.71-88.
MIRANDA, E. E.; GOMES, E. G.; GUIMARÃES, M. Mapeamento e estimativa da área urbanizada do Brasil com base em imagens orbitais e modelos estatísticos. In: Simpósio Brasileiro de Sensoriamento Remoto (SBSR), 12., 2005, Goiânia. Anais... São José dos Campos, p. 38133820.

MORAIS, J. S. Maputo: patrimônio da estrutura e forma urbana. Lisboa: Livros Horizonte, 2001.

NASCIMENTO Jr., L. Urbanização e cidade dispersa: implicações da produção do espaço urbano no Brasil, em Moçambique e na Austrália. GEOUSP: Espaço e Tempo (Online), v. 21, n. 2, p. 550-569, 2017.

NASCIMENTO Jr., L.. Transformações e permanências dos estudos comparados na geografia. Boletim Goiano de Geografia, v. 37, n. 2, p. 302-321, 2017.

NEWMAN, P. W. G; KENWORTHY, J. R. Sustainability and Cities: Overcoming Automobile Dependence. Washington, DC: Island Press, 1999.

NOAA. National Oceanic and Atmospheric Administration. Defense Meteorological Satellite Program - Operational Linescan System. Version 4 DMSP-OLS Nighttime Lights Time Series. Department of Commerce. Disponível em:

http://ngdc.noaa.gov/eog/dmsp/downloadV4c omposites.html. Acesso: 03 ago. 2014.

OJIMA, R; MONTEIRO, F. F; NASCIMENTO, T. C. L. Urbanização dispersa e mobilidade no contexto metropolitano de Natal: a dinâmica da população e a ampliação do espaço de vida. Urbe - Revista Brasileira de Gestão Urbana. 2015, vol.7, n.1, p.9-20.

OJIMA, R.; MARANDOLA Jr. E (Orgs.). Dispersão urbana e mobilidade populacional: implicações para o planejamento urbano e regional - São Paulo: Blucher, 2016.

OLIVA, J. O automóvel como elemento constituinte e constituidor da cidade de São Paulo. 2004. Tese (Doutorado em Geografia Humana)- Faculdade de Filosofia, Letras e Ciências Humanas da Universidade de São Paulo, São Paulo:USP,2004.

ONU. Organização das Nações Unidas. United Nations. World urbanization prospects: the 2011 revision. New York: United Nations, 2012. Disponível em: http://esa.un.org/unup/pdf/FINAL_REPORT\%20 WUP2011_Annextables_01Aug2012_Final.pdf. Acesso em: 17 set. 2014. 


\section{A DISPERSÃO URBANA EM MOÇAMBIQUE: UMA CONTRIBUIÇÃO AO ESTUDO DA PRODUÇÃO DO ESPAÇO URBANO EM MAPUTO}

RIBEIRO, R. J. da C; HOLANDA, F. de. Dispersão Urbana e Acessibilidade nas Metrópoles. Observatório das Metrópoles. 2010. Disponível em:

<http://www.observatoriodasmetropoles.net/d ownload/dispers\%C3\%A3o_e_acessibilidade.pd $\mathrm{f}>$. Acesso em: 20 de agosto de 2016.

SANTOS, M. A guerra dos lugares. In: SANTOS, M. O país distorcido: o Brasil, a globalização e a cidadania. [Organização de Wagner Costa Ribeiro] São Paulo: Publifolha, 2002,p. 87-89.

SANTOS, M. Por uma outra globalização - do pensamento único à consciência universal, Record, São Paulo, 2000.

SCHNEIDER, A.; FRIEDL, M. A.; POTERE, D. A new map of global urban extent from MODIS satellite data. Environmental Research Letters, v. 4, n. 4, p. 1-11,

SERRA, C. Chaves das portas do social (notas de reflexão e pesquisa). Maputo: Imprensa Universitária, 2012.

SILVA, Arménio. Dinâmica socioespacial e produção habitacional na periferia de MaputoMoçambique a partir da década de 1970: destaque para bairros Polana Caniço " $A$ " $E$ " $B$ ". Dissertação (Mestrado em Geografia) Universidade Federal de Santa Catarina. Santa Catarina, 2011.

SPÓSITO, M. E. B. Novas formas de produção do espaço urbano no Estado de São Paulo. In REIS, N. G.; TANAKA, M.S. (orgs.) Brasil, estudos sobre a dispersão urbana. São Paulo: FAUUSP/FAPESP, 2007, p. 7-28.

SPÓSITO, M. E. B. Segregação socioespacial e dispersão urbana. In: VASCONCELOS, P. de A; CORRÊA, R. L; PINTAUDI, S. M. (Orgs.) A Cidade Contemporânea: Segregação espacial. São Paulo: Contexto. 2010.

SPÓSITO, M. E. B. Notas em sala de aula da disciplina "Urbanização e cidades". 2014.

SQUIRES, G. D. Urban Sprawl: Causes, Consequences, \& Policy Responses. Washington: Urban Institute Press, 2002.

TANAKA, M. São José dos Campos: áres urbanas dispersas 1970 a 200․ In: REIS, N.; TANAKA, M. Brasil- estudo sobre dispersão urbana. São Paulo: FAU-USP, 2007, p.29-79.

THOMPSON, D. Suburban Sprawl: Exposing hidden costs, identifying innovations. (Report) University of Ottawa. October, 2013.

TSAI, Y-H. Quantifying urban from: compacyness versus "sprawl". Urban Studies, v.42, n.1, January, 2005, p.141-161.
ZHAO, Z; KAESTNER, R. Effects of urban sprawl on obesity. Journal of Health Economics, n. 29, 2010, p. 779-787.

ZHENG, P; BEATZ, B. GIS-Based analysis of development options from a hydrology perspective. Journal of Urban Planning and Development, v. 125 , n. 4, 1999, p. 164-180.

UNHABITAT. Perfil do sector urbano em Moçambique. Nairob: UNHABITAT, 2007.

VIANA, D. Maputo: entre cidade compacta, difusa e sem forma. Revista mensal de informações e debates do IPEA. 2010. Disponivel

em:

http://www.ipea.gov.br/desafios/index.php?op tion=com_content $\&$ view $=$ article\&id=1105: catid =28\&Itemid=23. Acessado em 26. jun. 2012.

VIANA, David L. RIVAS, Juan L. NATÁLIO, Ana. 2012. "Apreendendo com a morfologia urbana de Maputo [in]forma"I. ACTAS CONFERÊNCIAS INTERNACIONAL: PNUM 2012 - Morfologia Urbana nos Países Lusófonos. Lisboa. ISCTEInstituto Universitário de Lisboa, 2013, p. 601627.

VLETTER, F. Mozambique's Urban Informal Sector - A Neglected Majority. Maputo: Ministério do Trabalho, 2001.

WHO. Obesity and overweight. Fact sheet, World Health Organization. 2003. Disponível em:

<http://www.who.int/dietphysicalactivity/medi a/en/gsfs_obesity.pdf.>. Access in: 21 de October de 2014. 